\title{
The Structural Equation Model of Factors Influencing the Hotel Staff in Thailand's Intention to Quit
}

\author{
Pakorn Limyothin \\ Faculty of Management Sciences, Princes of Songkla University, Thailand \\ E-mail: pakornlim@gmail.com \\ Charlee Trichun \\ Faculty of Management Sciences, Princes of Songkla University, Thailand \\ E-mail: Charlee.t@psu.ac.th
}

Accepted: June 08, 2012 Published: July 09, 2012

Doi:10.5296/ijhrs.v2i3.2078 URL: http://dx.doi.org/10.5296/ijhrs.v2i3.2078

\begin{abstract}
The purpose of this research was to study the relationship among factors influencing the hotel staff in Thailand's intention to quit using the structural equation model gained from the review of related literature. The factors included quality of work life, perceived organizational culture, job satisfaction, organizational commitment and intention to quit. The population was the hotel staff in Thailand of which 908 were selected as subjects. The instrument used was a questionnaire with the reliability between 0.614-0.918. The data were analyzed using descriptive statistics and the structural equation model was analyzed using SPSS and LISREL. The results revealed that the supervisors had higher levels of work life quality, perceived organizational culture, job satisfaction and organizational commitment than the non-supervisors. Job satisfaction had the highest direct effect and the highest total effect. The variables in the model could explain the $56 \%$ of the variance $\left(\mathrm{R}^{2}\right)$ of the intention to quit.
\end{abstract}

Keywords: Intention to Quit, Hotel Business, Thailand

\section{Introduction}

Hotel business is operated 24 hours a day, 7 days a week with no holidays like other businesses. It is a complex system involving staff in diverse professions working together. They have different ideas, beliefs, experience and background but have to work under the 
same practice, policy, condition and organizational condition. This results in the different staff's work behavior (Kandasamy \& Ancheri, 2009).

The problem of the lack of workforce, though not a new one, is still the most crucial the hotel business in Thailand has to face with. This includes increasing labor cost and a lack of skilled labor in hotel business. Human resource administration is what the hotel business is attaching the importance to in terms of human resource planning both in high and low seasons (Lee \& Moreo, 2007), recruitment and selection, training and development. Moreover, as the hotel business aims to solve the problem of quitting, it is necessary to focus on the increasing of the quality of work life, perceived organizational structure, job satisfaction, and organizational commitment. These will help decrease the intention to quit, increase work efficiency, and finally achieve the organizational goals (Gray \& Liguori, 2003).

This research aimed at studying and developing the structural equation model (SEM) of factors influencing the hotel staff in Thailand's intention to quit. The results found will be beneficial to the academics in terms of knowledge broadening and to hotel administrators and hotel entrepreneurs in terms of planning in human resource administration to lessen the problems of insufficient workforce in the hotel business or related businesses.

\section{Literature review}

The study of concepts and related theories revealed the ways to explain the intention to quit and the psychological aspect was chosen to use in this research because it can explain all the factors intended to cover in the study. The motivation theories, both the content theories and the process theories, were chosen as the main theories in explaining the intention to quit. Motivation is the process that the body and the mind are stimulated by the stimulants for behavioral responses in order to achieve some goals. It can be seen that motivated people have energy and perseverance to achieve the aims so the administrators should attach importance to motivation in order to attract people with potential to join the organization, to encourage them to work efficiently and effectively and to keep competent staff with the organization (Sheldrake, 2003).

\subsection{Quality of work life}

Walton (1974), Bluestone (1977), Davis (1977), Delamotte (1984), Hodgetts (1993) and Casio (2006) similarly define the quality of work life as the condition in which the employees perceived that their needs in terms of work life balance have been satisfied. In working as a whole, they feel that their work is prestigious and suits their dignity and that they are given opportunities to participate in making decision about their own working condition. This, in turn, helps create job satisfaction which is good for them and enable them to efficiently achieve their work goals. Walton (1974) has specified 8 types of work life quality: adequate and fair compensation, safe and healthy working conditions, development of human capacity, growth and security, social integration, organizational constitutionalism, total life space, and social relevance. Delamotte (1984), however, divided work life quality into 5 dimensions 
consisting of traditional goals, fair treatment and work, influence of decisions, challenge of work content and work life, while Kandasamy \& Anceri (2009) divide it into 8 dimensions: job characteristics, person job fit, company image, human resource policies, work group relationship, physical working conditions, work life balance and interaction with customers.

\subsection{Perceived organizational culture}

Daft (1992), Wright (1995), Holfstede (1997) and Schermerhorn (1997) provide definitions of organizational culture which are in the same direction that it is the systems of behavior, values and shared beliefs that have been developed in the organization and become examples of behavior for members of the organization. It is the patterns of thought and feeling of members that have been defined cooperatively within the organization and hence make the members of that organization different from those of others. Tepeci (2002) divides organizational culture into 8 dimensions: team/people orientation, innovation, fair compensation, attention to detail, valuing customers, employee development, honesty and ethics and results orientation. Holfstede (2005) has developed a model with 8 dimensions including power distance, uncertainty avoidance, individualism, collectivism, masculinity, femininity, long-term orientation, and short-term orientation. Robbins (2007), however, specifies 7 characteristics of organizational culture: innovation and risk taking, attention to detail, outcome orientation, people orientation, team orientation, aggressiveness and stability.

\subsection{Job satisfaction}

There are two groups of theories explaining job satisfaction. The first is the group of content theories viewing human needs as can be seen via his behavior, i.e. needs can be estimated from the person's behavior. Examples of these are Maslow's Theory, ERG Theory, and Herzberg's Theory. The other is the process theory group which attaches the importance to the process that makes people satisfied rather than on their needs. It considers factors affecting personal satisfaction such as expectation, needs, values, etc. Some theories in this group are Equity Theory, Expectation Theory, and Achievement Needs Theory. From the definitions and the importance of job satisfaction stated above, it can be concluded that job satisfaction of hotel staff means the staff's admiration or satisfaction with the work they are responsible for and the factors involved with the work. Job satisfaction is divided into 2 types: intrinsic job satisfaction and extrinsic job satisfaction. Intrinsic job satisfaction means to like or to be satisfied with the type of work they are doing, using their potential to achieve success such as the use of their competence, job success, opportunities to do for others, freedom, opportunities for creativity and morale. Extrinsic job satisfaction means to like or to be satisfied with factors involving work conditions such as hotel policy administration, supervisors, income, work quantity, and job prospect (Robbins, 2007).

\subsection{Organizational commitment}

Sheldon (1971), Buchanan (1974) and Mowday (1982) similarly define organizational commitment as the workers' feeling that they can identify themselves with the organization, that they have similar values with other members of the organization, and that they are 
willing to devote themselves to carry on with the organization missions. These feelings are the results of the behavior that are tied to the organization with concentration on work in order to achieve the organizational goals. Buchanan (1974) divides the components of organizational commitment into 3: identification, involvement and loyalty whereas Steers (1991) divides them into personal characteristics, job characteristics and work experience. Meyer (1993) divides organizational commitment into 3 types: affective commitment, continuance commitment and normative commitment. Apart from that, Robbins (2007) divides it into initial commitment, commitment during early employment, commitment during later career.

\subsection{Intention to quit}

Kong et al (2004) defines intention to quit as the intention of the employees to voluntarily resign from the job they are doing, excluding being expelled from work. Intention to quit is an important variable in the estimation of the actual quit (Hom \& Griffith, 1995; Chen, 2006). Cho (2009), on the other hand, defines it as the probability in the near future that the employees will decide to quit the jobs they are doing or the intention to search for a new job that may yield more organizational commitment than their present one. Nadiri and Tanova (2010)'s definition is in concordance with this.

\section{Research methodology}

\subsection{Sample characteristics and procedure}

This study is a causal research. The population was the hotel staff in Thailand. The data were collected using a questionnaire which was examined by experts in both Thai and English. After that, five qualified experts performed the content analysis of the questionnaire (IOC=0.6-1.0) which was then tried out with 40 people and improved according to the information gained. 1,500 copies of the improved questionnaires were then sent out by post during January-February, 2012, using multi-stage method to select the subjects so the distribution in each region were in proportion to the number and size of the hotels. 903 copies $(60.2 \%)$ of the questionnaire were returned with complete responses.

\subsection{Measures}

The questionnaire consisted of 6 aspects: 1) personal information (10 items), 2) quality of work life ( 8 dimensions, 28 items), with $1-5$ rating scale $(\alpha=0.64-0.90)$, developed from Kndasamy and Anceri (2009), 3) perceived organizational culture (8 dimensions, 30 items), with 1-5 rating scale ( $\alpha=0.61-0.92)$, developed from Tepeci (2002), 4) job satisfaction consisting of 3 items with 1-5 rating scale ( $\alpha=0.88$ ) developed from Cammann et al (1979), 5) organization commitment consisting of 9 items, with $1-5$ rating scale $(\alpha=0.92)$ developed from Mowday et al (1982), 6) intention to quit including 3 items with 1-5 rating scale ( $\alpha$ $=0.77$ ) developed from Nadiri and Tanova (2010). 


\subsection{Statistical analysis}

Descriptive statistics were used in analyzing the data. In comparing the quality of work life, perceived organizational culture, job satisfaction, organizational commitment, and intention to quit of hotel staff in Thailand, t-test was used. The correlation and causal influence of all the variables (Figure 1) were analyzed using SPSS and LISREL for Windows with maximum Likelihood: ML in Two-stage Process (Anderson \& Gerbing, 1988). In interpreting the responses to questions with $1-5$ rating scale, the criteria used were: $4.50-5.00=$ most, 3.50-4.49 = much, 2.50-3.49 = moderate, $1.50-2.49=$ little, $1.00-1.49=$ least.

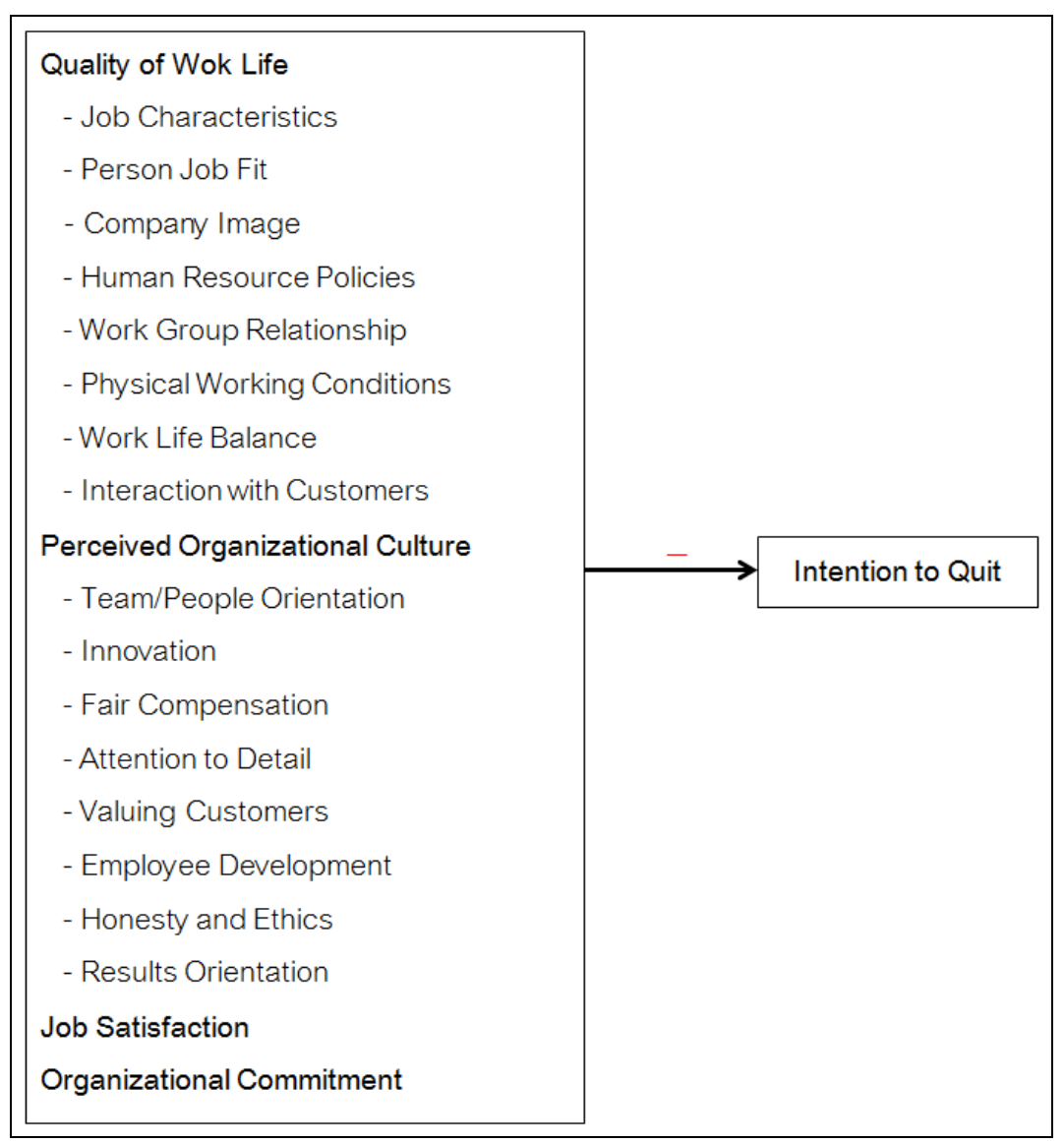

Figure 1 Conceptual Framework

\section{Results}

903 questionnaires with complete responses were sent back from 98 hotels in Thailand. The respondents were $66.2 \%$ females and 33.8\% males. Most had the average age of 25-35 years. $51.1 \%$ had their level of education lower than the university level and $45.5 \%$ were university graduates. Most (61.8\%) had the salary of less than 10,000 baht/month. Their work experience was distributed quite evenly from less than one year to more than 10 years. $65.3 \%$ were general staff and $34.7 \%$ were supervisors. $42.1 \%$ of the subjects were from small hotels while $57.9 \%$ were from large hotels. 
The highest average of quality of work life was of work group relationship which was at the high level (4.0495) and the lowest one was human resource policy which was at the moderate level (3.4615). The highest average of perceived organizational culture was of valuing customers which was at the high level (4.2481) and the lowest one was fair compensation which was at the moderate level (3.0926). Job satisfaction was averaged at the high level (3.6784). The organizational commitment was at the high level (3.8607) and the average of intention to quit was at the moderate level (2.6562). Supervisors had higher level of quality of work life, perceived organizational culture, job satisfaction, and organizational commitment than the non-supervisors. The Standard Deviation of every variable was between 0.6316-1.1031, Cronbach's Alpha between 0.614-0.918, the highest level of skewness of -1.1017 and the highest Kurtosis value of -0.858 (Table 1). The Pearson's Correlation values among the variables were between $0.24-0.74$ which was statistically significant at 0.01(Table2).

Table 1 Descriptive Statistics, Reliability, Skewness and Kurtosis

\begin{tabular}{|c|c|c|c|c|c|}
\hline \multirow{2}{*}{$\begin{array}{l}\text { Variables } \\
\text { Quality of Work Life }\end{array}$} & \multirow[t]{2}{*}{ Mean } & \multicolumn{2}{|c|}{ S.D. Cronbach's Alpha } & \multirow[t]{2}{*}{ Skewness } & \multirow[t]{2}{*}{ Kurtosis } \\
\hline & & & & & \\
\hline \multicolumn{2}{|c|}{ Job Characteristics (CHAR) 3.6530} & 0.5550 & 0.644 & -0.127 & 0.494 \\
\hline Person Job Fit (FIT) & 3.9611 & 0.8220 & 0.769 & -0.725 & 0.461 \\
\hline Company Image (IMAG) & 3.9111 & 0.8098 & 0.815 & -0.594 & 0.066 \\
\hline HR Policies (POLI) & 3.4615 & 0.9430 & 0.859 & -0.456 & -0.428 \\
\hline Work Group (RELA) & 4.0495 & 0.6434 & 0.895 & -0.761 & 0.697 \\
\hline Physical Working (PHIS) & 3.6556 & 0.9268 & 0.720 & -0.673 & 0.024 \\
\hline Work Life Balance (WLB) & 3.5463 & 1.1031 & - & -0.655 & -0.126 \\
\hline Interaction Cust. (INTE) & 3.7639 & 0.8231 & 0.774 & -0.534 & 0.185 \\
\hline \multicolumn{6}{|c|}{ Perceived Organizational Culture } \\
\hline Team Orientation (TEAM) & 3.9154 & 0.7390 & 0.874 & -0.728 & 0.123 \\
\hline Innovation (INNO) & 3.3490 & 0.7040 & 0.614 & -0.366 & -0.082 \\
\hline Compensation (COMP) & 3.0926 & 1.1012 & 0.918 & -0.230 & -0.858 \\
\hline Attention to Detail (DETA) & 3.8958 & 0.6521 & 0.754 & -0.577 & 0.541 \\
\hline Valuing Customers (CUST) & 4.2481 & 0.6854 & 0.848 & -1.017 & 0.817 \\
\hline Employee Develop.(DEVE) & 3.6074 & 1.0228 & 0.914 & -0.667 & -0.015 \\
\hline Honesty and Ethics (ETHI) & 3.7565 & 0.8635 & 0.633 & -0.825 & 0.465 \\
\hline Results Orientation (RESU) & 4.1593 & 0.7171 & 0.725 & -0.870 & 0.588 \\
\hline Job Satisfaction (JS) & 3.6784 & 0.8028 & 0.883 & -0.242 & -0.078 \\
\hline Organize Commitment $(\mathrm{OC})$ & 3.8607 & 0.6941 & 0.917 & -0.459 & 0.292 \\
\hline Intention to Quit (IQ) & 2.6562 & 0.8509 & 0.768 & -0.104 & -0.194 \\
\hline
\end{tabular}


Table 2 The Intercorrelation between the scaled variables

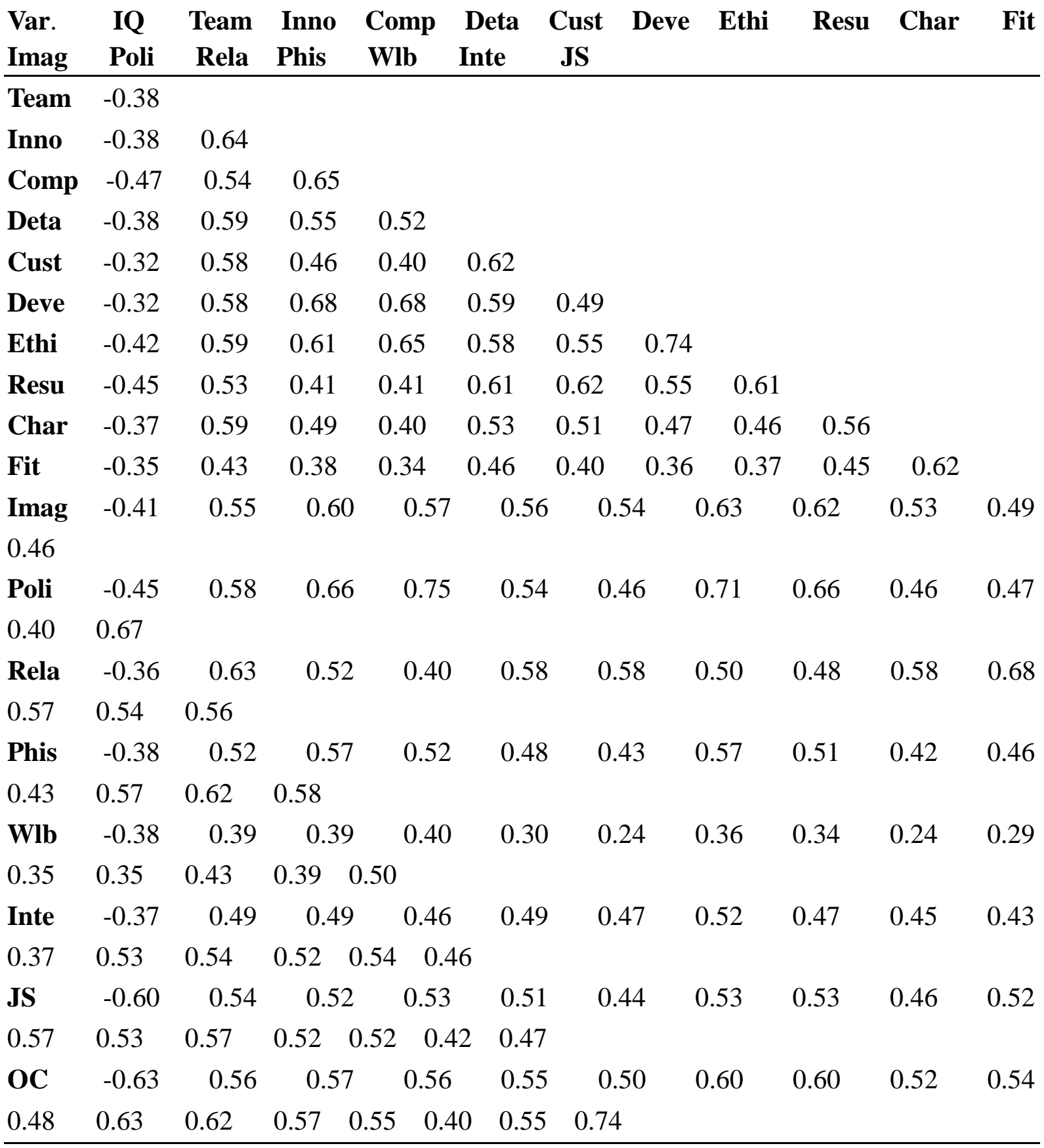

Significant at 0.01

The results of the development of the structural equation model of factors influencing intention to quit of hotel staff in Thailand had goodness of fit with empirical information at the high level with chi-square value of 5571.93, at the 1454 degrees of freedom, p-value of 0.00 , RMSEA value of 0.056, NNFI value of 0.98, CFI value of 0.99 and SRMR value of 0.050. Hence, it can be concluded that the Structure Regression Model (SR Model) developed from the model of Confirmatory Factor Analysis (CFA model) was in concordance with the empirical data (Figure2). Apart from that, the lowest Construct Reliability was 0.66 and the 
lowest Average Variance Extracted was 0.50 which was an acceptable level (Diamantopoulos \& Siguaw, 2000).

Table 3 is the consideration of the goodness of fits of the results in the important components of the model developed from the research framework. It was found that the standardized solution of the causal variance consisted of job characteristics (CHAR), person job fit (FIT), human resource policies (POLI), team/people orientation (TEAM), honesty and ethics (ETHI), work life balance (WLB), fair compensation (COMP), job satisfaction (JS) and organizational commitment (OC) affected the result variance in the model at the statistically significant level of 0.05 and 0.01 . This meant that the standard deviation was small. So it can be concluded that the model developed had goodness of fits with the empirical data of the results which were the essential component of the model.

Job satisfaction variance had coefficient influence both directly and indirectly on the intention to quit (direct effect $=-0.40$, indirect effect $=-0.15$ ) at the statistical significant level of 0.01. Likewise, organizational commitment has direct coefficient influence on intention to quit (direct effect $=-0.28$ ) at the significant level of 0.01. The Coefficient of Determination (R-Square: $\mathrm{R}^{2}$ ) of each endogenous latent variable was good which means that the variables in the model can explain $0.56 \%, 0.78 \%$ and $0.63 \%$ of the value of the variance of the intention to quit (IQ), organizational commitment (OC) and job satisfaction (JS) respectively.

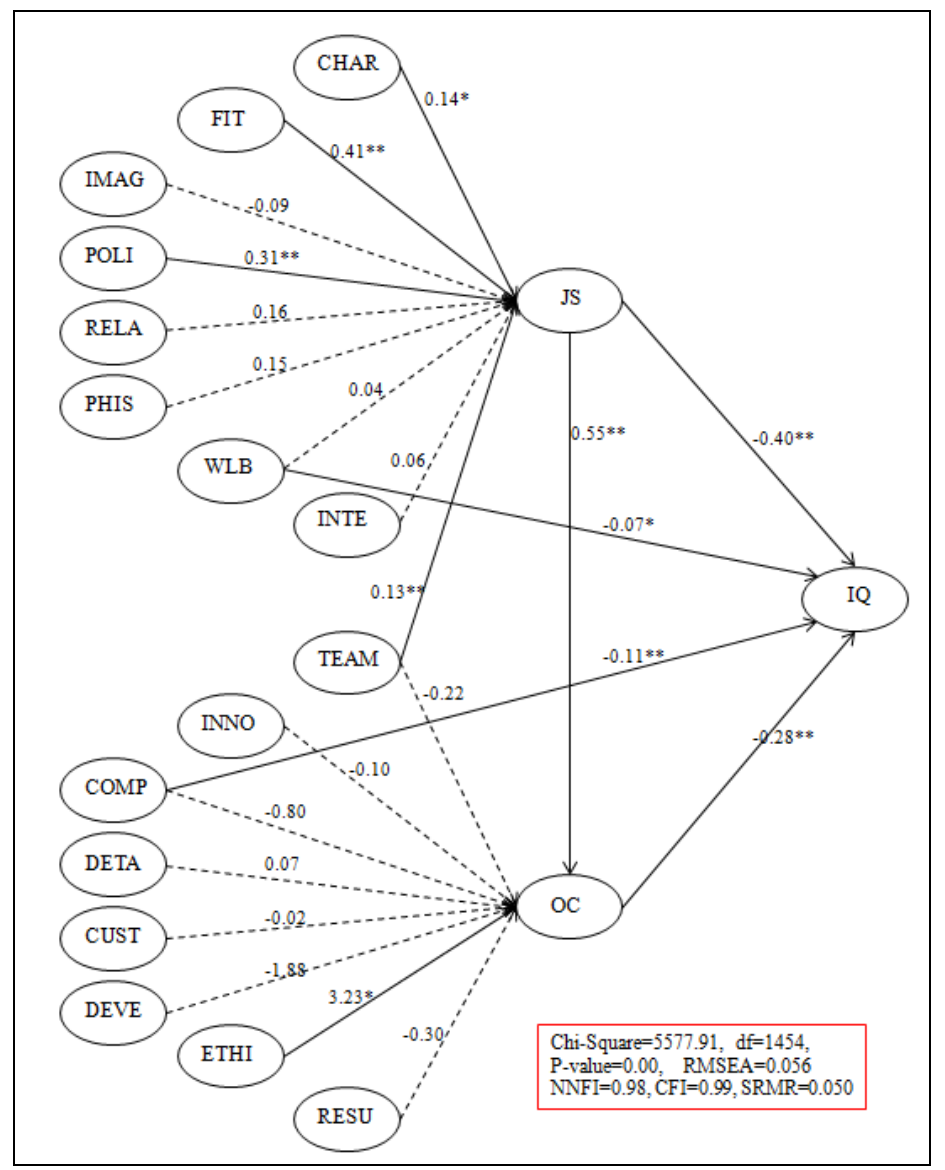

Figure 2 Structural Equation Model (Estimated Path Coefficients and Significant) 
Table 3 Testing the Impact of Variables: Coefficients

\begin{tabular}{|c|c|c|c|c|c|c|c|c|c|c|}
\hline \multirow[t]{3}{*}{ Variable } & \multicolumn{9}{|c|}{ Completely Standardized Solution } & \multirow[t]{3}{*}{$\mathrm{R}^{2}$} \\
\hline & \multicolumn{3}{|c|}{ JS } & \multicolumn{3}{|c|}{$\mathrm{OC}$} & \multicolumn{3}{|c|}{ IQ } & \\
\hline & $\beta$ & SE & $\mathrm{t}$ & $\beta$ & SE & $\mathrm{t}$ & $\beta$ & SE & $\mathrm{t}$ & \\
\hline$\overline{\text { CHAR }}$ & 0.14 & 0.07 & $2.14 *$ & - & - & - & - & - & - & - \\
\hline FIT & 0.41 & 0.06 & $6.34 * *$ & - & - & - & - & - & - & - \\
\hline IMAG & -0.09 & 0.07 & -1.43 & - & - & - & - & - & - & - \\
\hline POLI & 0.31 & 0.06 & $5.15^{* *}$ & - & - & - & - & - & - & - \\
\hline RELA & -0.16 & 0.10 & -1.67 & - & - & - & - & - & - & - \\
\hline PHIS & 0.15 & 0.10 & 1.51 & - & - & - & - & - & - & - \\
\hline WLB & 0.04 & 0.04 & 1.07 & - & - & - & -0.07 & 0.03 & $-2.39 *$ & - \\
\hline INTE & 0.06 & 0.05 & 1.16 & - & - & - & - & - & - & - \\
\hline TEAM & 0.13 & 0.05 & $2.48^{*}$ & -0.22 & 0.21 & -1.08 & - & - & - & - \\
\hline INNO & - & - & - & -0.10 & 0.22 & -0.46 & - & - & - & - \\
\hline COMP & - & - & - & -0.80 & 0.45 & -1.79 & -0.11 & 0.04 & $-3.09 * *$ & - \\
\hline DETA & - & - & - & 0.07 & 0.15 & -0.46 & - & - & - & - \\
\hline CUST & - & - & - & -0.02 & 0.17 & -0.14 & - & - & - & - \\
\hline DEVE & - & - & - & -1.88 & 1.01 & -1.87 & - & - & - & - \\
\hline ETHI & - & - & - & 3.23 & 1.58 & $2.05^{*}$ & - & - & - & - \\
\hline RESU & - & - & - & -0.30 & 0.20 & -1.50 & - & - & - & - \\
\hline JS & - & - & - & 0.55 & 0.05 & $11.30 * *$ & -0.40 & $0.05-$ & $-7.27 * *$ & 0.63 \\
\hline $\mathrm{OC}$ & - & - & - & - & - & - & -0.28 & 0.06 & $-4.94 * *$ & 0.78 \\
\hline IQ & - & - & - & - & - & - & - & - & - & 0.56 \\
\hline
\end{tabular}

\section{Discussion and implications}

The study of structural equation model with causal factors consisting of organizational commitment, job satisfaction, perceived organizational culture and quality of work life and the resulting variables of intention to quit was able to explain 56\% of the variance of the intention to quit of hotel staff in Thailand. This meant that some hidden involving variables have not yet been selected to include in the model. If the involving variables such as conflicts in work or opportunities in changing work are included, it may be possible to better explain the variance in the intention to quit of hotel staff.

Attitude toward work has been a variable widely studied and they are very important in the explanation of behavior of the staff in the organization especially job satisfaction and organizational commitment. The results of the study found that job satisfaction and organizational were negatively related to the intention to quit. The structural equation model analysis found that organizational commitment directly affected the intention to quit whereas job satisfaction directly affected the intention to quit and indirectly affected organizational commitment, resulting in the total influence of 0.55 . It can be seen, then, that job satisfaction is very crucial to the intention to quit. It was also possible that the work condition of hotel 
staff requires them to work continuously because hotel business is the business around the clock, with no holidays like other businesses. Hence, it is crucial to attach importance to the work characteristics, suitability, human resource policies and team work. Having various staff with a lot of differences in each level, the hotel business has to administer fair compensation. Though the hotel business yields both monetary and non-monetary gains, the present economic conditions of today and the diversity of each individual make it difficult to administer fair compensation which also suits the staff in each department and in different levels, as well as in different types of hotels. The human resources department of each hotel needs to bring in the job evaluation system for use. This is the process in finding the relationship between compensation and responsibilities of the jobs in the organization in order to calculate the compensation as pay. So the group of variables in quality of work life and perceived organization culture are crucial causal factors affecting job satisfaction, organizational commitment and finally intention to quit.

Important variables directly affecting the intention to quit of hotel staff in Thailand are the variables in job satisfaction, organizational commitment, fair compensation, and work life balance. It shows that if the hotel staff are paid fairly and have work life balance, they will have only little intention to quit. And if they have high job satisfaction and organizational commitment, the intention to quit will be less. Hence, the hotel administrators should be aware of these variables and use them in organizing activities that will raise the level of job satisfaction of the staff. This can be fair compensation for everyone, improving the quality of administration to reduce conflicts, distribute power in administration in the organization, assigning work suitable to the staff's interest, letting the staff participate, building trust and secured job condition as well as job prospect, etc.

Organizational commitment is the attitude that reflects the relationship between the staff and the organization. To make them commit to the organization, quality of work life must be built because quality of work life has impact on the person and organization both at the micro and macro levels. In addition to that, the present development current in work life quality has been accepted and in the interest of many countries including Thailand. Organizations in Thailand are aware of the importance of it and have focused on the development and promote the quality of work life for their staff because they see the importance of human resource and living together in the society. However, though various components of work life quality are receiving more attention, it doesn't mean that work life quality can be achieved immediately and tangibly. This is because work life quality is the issue of wide covering and abstractness so it needs to rely on the criteria in work life quality evaluation to evaluate the work life quality of the staff, for example, appropriate and fair compensation, safe and healthy work condition, opportunities in using and developing the staff's potential, security and job prospects, etc. The building of work life quality, hence, has a tendency to become an important issue challenging the administrators in the future because employing staff especially those skilled or knowledgeable ones cannot be done only by giving high salary and benefits. The organization, thus, has to specify the policies which are clear and concrete in order to develop work life quality and this has to be done continuously and systematically. 


\section{Limitations and recommendations for future research}

The research design using structural equation model in analyzing the data should consider easing its initial agreement by allowing the residuals in measuring variables to correlate with one another so that the structural equation model can have better goodness of fits with the empirical data. This is because the characteristics of the relationships among variables related to the intention to quit are taken from many concepts and theories. It is a complex relationship so the residuals in measuring the variables may correlate. When one variable changes, others will be affected. The residuals may occur because of the following reasons (Wiratchai, 1995): 1. the results from unknown variables not included in the model, 2. the results from known variables but intentionally not included in the model, 3. the randomness of human behavior and 4. measurement error. So the study and analysis of the factors influencing the intention to quit of hotel staff in Thailand should consider them in such a way that allows the residuals in the measurement of these variables to correlate.

In the study of structural equation model of components influencing the intention to quit of hotel staff in Thailand, the population is rather highly different in each category and size of the hotel. Hence, the study should focus on each type or each size of hotels or a comparison of models should be made so as to arrive at the structural equation model specific to each type or size of hotel. Besides, the study of models should be made to compare supervisors and non supervisors, the intention to quit or intention to stay or other resulting variables such as performance or organizational citizenship behaviors to analyze and compare the models, magnitude and direction of influence on each variable and model to find out how they are similar or different.

\section{7. acknowledgment}

I wish to express my deep appreciation to Dr. Charlee Trijan, Assoc. Prof. Dr. Sanguan Lerkiatbandit and Assit. Prof. Dr. Jutharat Sathirapanya for their valuable guidance and contributions to this study. Many thanks to Dr. Elizabeth Hiser and Dr. Laila Hussain, the Massey University, New Zealand, for their useful comments and suggestions. In addition, I wish to thank the Hatyai University for supporting scholarship that enabled me to complete the study.

\section{References}

Bluestone, I. (1977). Implementing Quality of Work Life Program. Management Review, 4 (July 1977), 43-46.

Bolen, K. A. (1989). Structural Equations with Latent Variable. New York: John Wiley \& Sons, Inc.

Buchanan, B. (1974). Building Organizational Commitment : The socialization of managers in work organizations. Administrative Science Quarterly 
Cameron, K. S. \& Quinn, R. E. (1999). Diagnosing and changing organizational culture, Reading, MA: Addison-Wesley.

Cammann, C., Fichman, M., Jenkins, D., \& Klesh, J. (1979). The Michigan organizational Assessment questionnaire, Ann Arbor, MI: University of Michigan.

Casio, W. F. (2006). Managing Human Resources : Productivity, Quality of Work Life, Profits. $7^{\text {th }}$ ed. McGraw-Hill Company.

Chen, C. F. (2006). Job Satisfaction, organizational commitment, and flight attendants' turnover intentions : A note. Journal of Air Transport Management, 12, 274-276.

Cho, S., Johanson, M. M. \& Guchait, P. (2009). Employees intent to leave: A comparison of determinants of intent to leave versus intent to stay. International Journal of Hospitality Management, 28, 374-381.

Daft, R. L. (1992). Essentials of Organization Theory and Design. Cincinnati, Ohio: SouthWestern.

Davis, L. E. (1977). Enhancing Quality of Working Life: Developments in The United States. International Labour Review, 116 (July-August 1977), 53-65.

Dawson, B. \& Trapp, R. G. (2001). Basic and clinical biostatistics. $3^{\text {rd }}$ Ed. Boston: Lange Medical Books.

Delamotte, Y. \& Takesawa S. (1984). Quality of working life in international perspective. Geneva: International Labour Office.

Diamantopoulos, A. \& Siguaw, A. D. (2000). Introducing LISREL: A guide for the unimaultiated. Sage Publication, London.

Gray W.S. and Liguori S.C. 2003. Hotel and motel management and operations. Pearson Education-indochina Ltd.

Griffeth, R. W., Hom, P. W. \& Gaertner, S. (2000). A meta-analysis of antecedents and correlates of employee turnover: Update, moderator tests, and research implications. Journal of Management, 26, 463-88.

Hair, J. F., Anderson, R. E., Tatham, ～R. L. \& Blanck, W. C. (2010). Multivariate Data Analysis with Readings. $4^{\text {th }}$ ed. Englewood Cliffs, New Jersey : Prentice-Hall.

Hodgetts, R. M. (1993). Modern Human Relation Work. $5^{\text {th }}$ ed. Florida: The Dryden Press Harcourt Brace Jovanovich College Publishers.

Hofstede, G. H. (1997). Culture and Organizational: Software of the Mind. United States: McGraw-Hill.

Hofstede, G. H. \& Hofstede, G. J. (2005). Cultures and Organizations: Software of the Mind. New York: McGraw-Hill.

Hom, P. W., Caranikas, F., Prussia, G. E., \& Griffeth, R. W. (1992). A meta-analytical structural equations analysis of a model of employee turnover. Journal of Applied Psychology, 77, 890-909.

Hom, P. \& Griffeth, R. (1995). Employee turnover. Cincinnati, OH: South-Western.

Hom, P. W. \& Griffeth, R. W. (1995). The employee turnover process. Research in Personnel and Human Resources Management, 13, 245-293.

Kandasamy, I. and S. Ancheri, 2009. Hotel employees' expectations of QWL : A qualitative study. International Journal of Hospitality Management 28, 328-337. 
Karatepe, M. O. \& Uludag, O. (2007). Conflict, exhaustion, and motivation: A study of frontline employees in northern Cyprus hotels. International Journal of Hospitality Management, 26, 645-665.

Kim, G. W. \& Leong, K. J. (2005). Effect of service orientation on job satisfaction, organizational commitment, and intention of leaving in a casual dining chain restaurant. International Journal of Hospitality Management, 24, 171-193.

Kong, S. X., Wertheimer, A. I., Serradell, J., \& McGhan, W. F. (2004). Psychometric evaluation of measures of organizational commitment and intention to quit among pharmaceutical scientists. Phamaceutical Res, 11, 171-180.

Kwantes, C. T. \& Boglarsky, C. A. (2007). Perceptions of organizational culture, leadership effectiveness and personal effectiveness across six countries. Journal of International Management, 13, 204-230.

Lee, C. and P.J. Moreo, 2007. What do seasonal lodging operators need to know about seasonal workers? International Journal of Hospitality Management. 26, 148-150.

Meyer, P., Allen N. \& Smith C. (1993). Commitment to organizations and occupations: extension and test of a three - component conceptualization. Journal of Applied Psychology, 25, 538-551.

Mowday, R. T., Porter, L. W. \& Steer, R. M. (1982). Employee organization linkage: The psychology of commitment, absenteeism and turnover. New York: Academic Press.

Nadiri, H. \& Tanova, C. (2010). An investigation of the role of justice in turnover intentions, job satisfaction, and organization citizenship behavior in hospitality industry. International Journal of Hospitality Management, 29, 33-41.

Ohana, M., \& Mayer, M. (2010). Should I stay or should I go now? Investigating the Intention to quit of the permanent staff in social enterprises. European Management Journal, 28, 441- 454.

Robbins, S. P. \& Timothy, A. J. (2007). Organizational Behavior. $12^{\text {nd }}$ ed. New Jersey: Pearson Education.

Schermerhorn, J., Hunt, J. G., \& Osborn, R. N. (1997). Organization Behavior. $6^{\text {th }}$ ed. New York: John Wiley \& Sons, Inc.

Sheldon, M. E. (1971). Investments and Involvement as Mechanism Producing Commitment to Organization. Administrative Science Quarterly, 16, 143-150.

Sheldrake, J., 2003. Management Theory. Second Edition. Thomson Learning. London.

Steers, R.M., (1991). Introduction to Organization Behavior. $4^{\text {th }}$ ed. New York: Harper Collins.

Susskind, M. A. (2000). Customer service employees' behavioral intentions and attitudes: An examination of construct validity and a path model. International Journal of Hospitality Management, 19, 53-77.

Tepeci, M., Bartlett, B. (2002). The hospitality industry culture profile: a measure of individual values, organizational culture, and person-organization fit as predictors of job satisfaction and behavioral intentions. Hospitality Management, 21, 151-170.

Walton, R. E. (1974). Improving The Quality of Work Life. Harvard Business Review, 4, 12-14. 


\section{Macrothink}

International Journal of Human Resource Studies

ISSN 2162-3058 2012, Vol. 2, No. 3

Wiratchai, N. (1995). Linear Structure Relationship for Social Science. Bangkok.

Chulalongkorn University.

Wright, P. M. \& Raymond, A. N. (1995). Management of Organization. U.S.A.: Von Hoffman Press, Inc. 